\title{
Enterprise Internal Control from the Perspective of Risk Management
}

\author{
Yan WU \\ Jilin Business and Technology College, \\ Changchun City Jilin Province, China \\ Email;wuyan20050305@163.com
}

\begin{abstract}
The global financial crisis has brought unprecedented challenges to the existing risk management model. The actual course of business, risk management and internal control are inextricably linked. Starting from the evolution and development process of risk management and internal control, the article analyzed the relationships between risk management and internal control, pointing out the problems in the enterprise risk management, and then proposed new mechanisms for constructing a comprehensive risk management of internal control.
\end{abstract}

Keywords- Risk Management; Internal Control; Relationship; Problems; New Mechanism

\section{I..INTRODUCTION}

The global financial crisis which was triggered by the U.S. subprime mortgage crisis that caused people questioned the role of the internal risk management mechanism. In fact, after the Asian financial crisis, some countries of the world have realized the importance of risk management, and have established a risk management mechanism. However, risk management is difficult to integrate into the day-to-day operation within the management of enterprises, thus they can not be fully put into practice. From this point of view, the financial crisis has brought unprecedented challenges to the existing risk management model. Internal control which is considered as an important part of the risk management has important practical significance on the efficiency and effectiveness of enterprise risk management. The paper intends to discuss the control problems from the point of risk management so as to provide a reference for enterprise on how to improve the level of risk management and to establish a sound internal control system.

\section{RELEVANT THE ORETICAL CONCEPTION}

\section{A. Conception of Risk Management}

Risk management is to take some measures to evaluate the risk , thus it can be controlled at an acceptable level. COSO (a professional organization which include the IIA and AICPA Alliance) on risk management made the following definition on risk management: "a comprehensive risk management is a process and it is influenced by the board of directors, managements and other personnel of the enterprise. The process starting form the strategy formulation has been run through the activities of the enterprise, and used to identify the potential events and the management risk that may affect the enterprise, thereby to ensure the enterprises to achieve the established goals.” Some domestic economists believed that risk management is the scientific management methods which means through the identification, measurement and analysis of a potential accident or loss, the enterprise can effectively control the risk to achieve maximum security with the most economical and reasonable way on this basis, which can be understood as: risk management is a systematic process, including identification, measurement and control of risk. The goal of risk management is to control and reduce the losses, and improve the economic benefits or social effects for the relevant units or individuals; risk management is a management method.

\section{B. The conception of internal control}

COSO defines the internal control as follows: Internal control is a process which intends to achieve the effectiveness and efficiency of operations and the reliability of financial reporting, following the laws and regulations to provide the reasonable assurance, which is affected by the board of directors, management and other staff within the enterprise. Internal control includes five elements, ${ }^{[1]}$ just is shown as follows in Fig 1.

- Environment control: refers to a set of factors which have a significant effect on the establishment and implementation of enterprise control, including the management philosophy, management method, organization structure, human resources policies and practices, the board of directors and so on.

- Risk assessment: is a key to improve the efficiency and effect of internal control, which includes risk identification and risk analysis.

- Activities control : refers to the establishing policies and procedures which aim to ensure the achievement of corporate goals including performance evaluation, information processing and control, physical control, separation of duty.

- Information communication: refers to the effective information transferring in the internal enterprise top-down, bottom-up, transversely and between enterprises and outside environment, which helps to improve the efficiency and effectiveness of internal controls, thus it can provide the accurate and comprehensive information the production and management decision-making timely.

Supervision: refers to a process which continuously evaluates the enterprise's internal control framework with the lapse of time and the internal and external factors changes. 


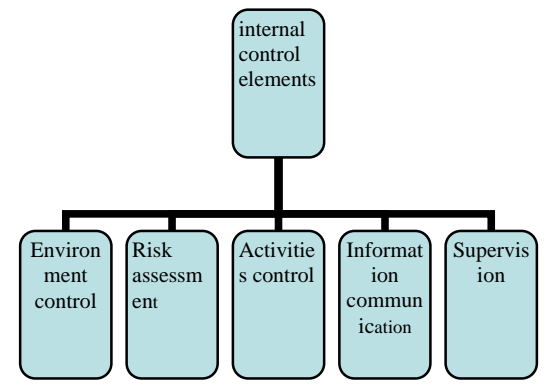

Fig 1. Internal control elements form

\section{III.RISK MANAGEMENT AND INTERNAL CONTROL RELATIONSHIPS}

The author believed the exploration of enterprise risk management and internal control and the true understanding for the main difference and connection between them benefits correctly grasping the relationship between the two which may improve enterprise management theory further and has a great significance on promoting the business management practice.

\section{A. Relationship between risk management and internal control}

- Process of cognition on internal control and risk management

In 1992 The sponsoring organizations of The United States National Commission of fraudulent financial reporting Committee (COSO) proposed the idea of "internal control". In 2004 it is changed as "risk management". In 1992, its content includes 5 elements, while in 2004 includes 8 elements, ${ }^{[2]}$ which indicates that the awareness of the problem is a process. I think that the internal control is the basis and the essential part of risk management. They are integrative and inseparable.

- Internal control is to solve the conventional risk, risk management is to solve non-routine risk.

Internal control is to solve the "how to do things right", and risk management is to solve the "how to do the right thing". They have connection and distinction. Metaphorically speaking, internal control is similar to drive the car, while risk management is similar to look up the road conditions. A enterprise want to succeed, need to drive the car and look up the road conditions. Neither of the two can be dispensed.

B. The difference between risk management and internal control

The concept of "The enterprise risk management" does not mean abandoning the original "internal control" concept. As COSO committee pointed out, the internal control is an integral part of the enterprise risk management; the framework of the enterprise risk management did not replace the internal control, but include the internal control. Not only the company can use the framework of enterprise risk management to meet their internal control needs, but also can shift to a more comprehensive risk management process. So in the view of COSO, enterprise risk management covers internal control, is a more comprehensive, broad concept. Thus, the difference between the two mainly includes the following aspects:

- The enterprise risk management covers internal control

From the view of enterprise risk management framework, including the original three internal control targets, and also the strategic goal; enterprise risk management has eight elements besides the five elements of the original internal control, also added ,the goal setting, event identification and risk response, three elements.

- The enterprise risk management emphasis on risk control and Countermeasures

Risk management includes risk planning, risk control and risk response. The three together constitute a complete risk management process. Among them, the risk control can be divided into external and internal control. It is stressed that, the internal control is an internal risk control mechanism; internal control is different from risk management. The main job for risk management is to make risk plan. Risk control has carried out a variety of control activities under the risk plan. Risk control includes internal risk control and external risk control.

\section{THE PROBLEMS EXISTING IN THE CURRENT WORK OF ENTERPRISE RISK MANAGEMENT}

The uncertainty of enterprise's management environment and regulatory requirements of enterprise risk management, make Chinese enterprises increasingly concerned with risk management and set up a special risk management mechanism to the management of risk. But because our country enterprise risk management is still in the development stage, most enterprise did not form a system, complete risk management system. therefore, at present our country enterprise risk management still exist the following problems:

A. Managers of enterprises and the related personnel risk awareness is weak.

Strengthen the enterprises' environment control and risk assessment, is to improve the efficiency and effect of the enterprises. But the Chinese enterprises are lack of a recognizable, analysis and risk management mechanisms. As a result, in order to pursuit the high returns, blind investment risk occurred frequently.

B. Existing risk management mechanism is not enough to cope with the risks of enterprise.

Because our country enterprise risk management mechanism designed late, existing regulations system is also implemented in recent years, but, enterprises are facing the fast changing external environment. The fast changing business environment may make the risk management mechanism weak and even failure.

\section{The construction of risk management organization is not perfect.}

In June 6, 2006, State Asset Management Commission of The State Council issued the "central government - owned 
companies’s risk management guidelines" Article 42 clearly stipulates: "the enterprise should build perfect risk management system, mainly including a standardized corporate governance structure, risk management department, internal audit department and the legal department and other relevant departments, the business unit organizational structure and responsibilities.”

D. Risk management institutions are lack of independence.

As a part of enterprise internal audit, risk management institutions have the problems of independent. Especially most of the Chinese enterprises' risk management departments are not perfect, system, audit staff duties are not clear, the responsibilities of the enterprise risk are not clear, which caused the risk management can not play the role of supervision.

\section{CONSTRUCT THE COMPREHENSIVE RISK MANAGEMENT OF THE INTERNAL CONTROL MECHANISM}

Because of the weak risk management mechanism, internal control play a key role in risk management, in order to improve the level of enterprise risk management, enterprises should do the followings aspects to strengthen internal control, improve the level of enterprise risk management.

A. Construction of the enterprise innovation risk management concepts

Regarding the comprehensive risk management as part of corporate culture, is a new concept. This concept becomes the corporate culture also needs time, it needs all staff's efforts in the comprehensive risk management. ${ }^{[3]}$ Therefore, study and learn from other enterprise risk management skills and experience, actively explore the new method for the enterprise internal control and management, only in this way, the comprehensive risk management concept can truly integrate to the real work, creating a good risk management culture, improving the internal environment, the comprehensive risk management system can be developed.

B. Building a realistic appraisal of the internal control mechanism

Under the traditional mode, due to the lack of a uniform risk management judgement, each functional departments are the risk management authority, the long-term management responsibilities' stability ensures the authority, a serious lack of each post duty of active tracking evaluation system. ${ }^{[4]}$ As post duty supervisor of the audit department was "a routine check". Therefore, enterprises should according to their own actual situation, through the identification of risk control, the implementation of the post management responsibilities of various departments. The Department of control status were regular inspected, evaluated and examined. Strengthening risk management responsibilities, improve the overall risk prevention awareness and ability. Thus effectively promoting the comprehensive risk management, implementation from department risk prevention to total enterprise, internal control management from individual behavior to enhance enterprise's overall behavior, make the enterprise internal management improved to the new level.

\section{C. .Construction of the new internal control system principle}

- Comprehensive risk management principles.

Internal control must follow a comprehensive risk management principles: management principles for all the staff, strengthen the risk consciousness and put into the action; the whole process management principle supervise the risk during the development of enterprises and business operation; all-round risk management principles, not only including the business risk, but also includes the investment risk, credit risk, and contract risk.

- Hierarchical management principles.

Risk management's decision-making, management, operational function are given to different levels of organization, forming the Pyramid type organization structure.

- Advanced risk management principles.

The risk of daily monitoring functions directly provided to the business sector, make risk management more close to the market. It is good for detection of risk, risk control. It also shows that characteristics of risk management and business management are parallel operation.

- Coordination and efficiency principle.

To ensure the department responsibilities clear, convenient operation; To guarantee the communication between department is convenient, quick, accurate, ensuring the efficient operation of enterprise management system

D. Construct the new management system which conform to the requirement of internal control

By using the traditional risk management mode, in order to ensure the conduct of the business smoothly and against all kinds of risks, various functional departments developed a large number of so-called "comprehensive" regulations. But they lost their practical significance, being the one which was post on the wall or written in books. The operation of the system is poor validity. The main reason is the system is lack of scientific planning. ${ }^{[5]}$ Therefore, on the premise of the internal control requirements, we must sort out the existing rules and regulations, further improve the supply and marketing business, accounting business, intermediate business, and integrate of all the business operation process, to establish a system which covers all business products and related business, and realize the synchronization of business development and risk management. Basic unit should strengthen the self-examination of rules and regulations and risk control, forming a regular inspection of lasting system. Internal audit departments should give full play to the role of audit to promote, encourage enterprises to gradually establish the business management and business assessment according to the unified standard in the management of the new system.

To sum up, to establish and perfect the risk based management of enterprise from the perspective of the internal control mechanism, improve the leave of enterprise dealing with the risk, which has a great significance for the 
enterprise to develop stable and rapidly.

\section{REFERENCES}

[1] Committee of Sponsoring Organizations of the Treadway Commission (COSO),Internal Control-Integrated Framework,1992

[2] COSO Enterprise Risk Management Framework[R].2003.

[3] Xiaogeng Chen. " On the Necessity of Constructing the System of Comprehensive Risk Management " $[\mathrm{J}]$. Friend of the Accountants 2008,(9);35

[4] Jinping Yan. "On the Internal Control Mechanism of Modern Enterprises“ [J].Modern Management Science, 2007, (1);21

[5] Maijoor,S. “The internal control explosion,International” [J].Journal of Auditing,2000(4);101-109 